\title{
Ferroelectric Relaxor Behavior and Spectroscopic Properties of Ba2+ and Zr4+ Modified Sodium Bismuth Titanate
}

\author{
B. Tilak \\ Department of Materials Science, Addis Ababa University, Addis Ababa, Ethiopia
}

\begin{abstract}
Polycrystalline ceramics $\left(\mathrm{Na}_{0.5} \mathrm{Bi}_{0.5}\right)_{1-\mathrm{x}} \mathrm{Ba}_{\mathrm{x}} \mathrm{Zr}_{\mathrm{y}} \mathrm{Ti}_{1-\mathrm{y}} \mathrm{O}_{3}$, (BNBZT) (for $\mathrm{x}=0.10,0.12 ; \mathrm{y}=0.04$ ), has been synthesized by conventional solid-state sintering. X-ray diffraction analysis indicates the formation of a single phase with tetragonal symmetry with pure perovskite structure. Scanning electron micrograph of the studied materials shows a distribution of grains. A broad dielectric peak with maximum permittivity has been observed near 1200 (for $\mathrm{x}=0.10, \mathrm{y}=0.04$ ) and 1600 (for $\mathrm{x}=0.12, \mathrm{y}=0.04)$ respectively in the temperature range, $\mathrm{RT}-600^{\circ} \mathrm{C}$. This result indicates that these materials may have great potential for a variety of high temperature applications. These ceramics show diffuse phase transition and the transition temperature shifting toward higher temperature with increasing frequency, which represents the relaxor behvaiour. The relaxor materials obey modified Curie-Weiss law and Vogel-Fulcher relationship. The values of the diffuseness parameter $\gamma=2$ for $\mathrm{x}=0.10$ and 1.67 for $\mathrm{x}=0.12$, obtained from the fit of a modified Curie-Weiss law established the relaxor type nature. For a more detailed interpretation of the ac data, the complex impedance $\left(Z^{*}\right)$ and electric modulus $\left(M^{*}\right)$ as a function of frequency $f$ (i.e., $45 \mathrm{~Hz}-5 \mathrm{MHz}$ ) has been simultaneously analysed. Impedance study reveals that there exists a temperature dependent electrical relaxation phenomenon in the materials. Modulus represents hopping of ions and localized motion in studied compositions. Conductivity obey's Jonscher law
\end{abstract}

Keywords Polycrystalline, lead-Free relaxors, Vogel-Fulcher relation, Impedance, Modulus, Conductivity

\section{Introduction}

Lead-based complex perovskite relaxor ferroelectrics, such as $\mathrm{Pb}\left(\mathrm{Mg}_{1 / 3} \mathrm{Nb}_{2 / 3}\right) \mathrm{O}_{3}(\mathrm{PMN}), \mathrm{Pb}\left(\mathrm{Zn}_{1 / 3} \mathrm{Nb}_{2 / 3}\right) \mathrm{O}_{3}$, and the derived compounds, are widely used in the fabrication of multilayer ceramics capacitors, hysteresis-free actuators, and high performance sensors because of their excellent dielectric and piezoelectric properties.[1-4] However, these lead based relaxor ferroelectrics contain more than $60 \mathrm{wt} \%$ lead.[5,6] Lead is a very toxic substance, which can cause damage to the kidney, brain, and nervous system, especially the intelligence of the children.[7] In recent years, therefore, some countries have required all new electronic products to be lead-free for the environmental protection and human health.[8] Hence, many studies are focused on the Ba$\mathrm{TiO}_{3}$-based materials such as $\mathrm{BaTiO}_{3}-\mathrm{BaZrO}_{3}$,[9] $\mathrm{Ba}$ $\mathrm{TiO}_{3}-\mathrm{BaSnO}_{3},[10] \mathrm{BaTiO}_{3}-\mathrm{BiAlO}_{3},[11]$ and $\mathrm{BaTiO}_{3}-$ $\mathrm{CaTiO}_{3}-\mathrm{SrTiO}_{3}[12]$ because these $\mathrm{BaTiO}_{3}$-based lead-free relaxor ferroelectrics show relatively high dielectric and

* Corresponding author:

tilakb22@rediffmail.com (B. Tilak)

Published online at http://journal.sapub.org/materials

Copyright (C) 2012 Scientific \& Academic Publishing. All Rights Reserved piezoelectric properties among the lead-free relaxor ferroelectrics. Unfortunately, these $\mathrm{BaTiO}_{3}$-based lead-free relaxor ferroelectrics show low temperature of the maximum dielectric permittivity $(\mathrm{Tm})$. This temperature $\left(<100^{\circ} \mathrm{C}\right)$ is not high enough to use these materials in high temperature fields, such as automotive, aerospace, and related industrial applications.[13] Therefore, currently, much effort has been placed on the study of searching and developing the new lead-free or lead-reduced relaxor ferroelectrics for high temperature applications[14-16].

The NBT is an excellent example of lead-free relaxor ferroelectrics in order to develop for high temperature applications. In literature review, the dielectric, ferroelectric and piezoelectric properties of typical lead-free perovskite ferroelectric ceramics such as $\mathrm{BaTiO}_{3}$ (BT)-based, $\left(\mathrm{Na}_{0.5} \mathrm{Bi}_{0.5}\right) \mathrm{TiO}_{3}(\mathrm{NBT})$-based and $\mathrm{KNbO}_{3}(\mathrm{KN})$-based systems for actuator and high- power applications and also BLSF ceramics such as $\mathrm{Bi}_{4} \mathrm{Ti}_{3} \mathrm{O}_{12}$ (BIT)-base, $\mathrm{Bi}_{3} \mathrm{TiTaO}_{9}$ (BTT) -based and ( $\mathrm{Sr} \mathrm{Ca})_{2} \mathrm{Bi}_{4} \mathrm{Ti}_{5} \mathrm{O}_{18}(\mathrm{SCBT})$ systems for ceramic resonator applications are desired as superior candidates for environmental friendly, lead-free piezoelectric materials to reduce some damage to earth. Among the NBT based system, (1-x) $\mathrm{Bi}_{0.5} \mathrm{Na}_{0.5} \mathrm{TiO}_{3}-\mathrm{xBaTiO}_{3}$ posses rhombohedral (FR) - tetragonal (FT) morphotropic phase boundary (MPB) at $x=0.06-0.07[17]$. Gao et al reported the 
composition (1-x) $\mathrm{BaTiO}_{3}-\mathrm{xBi}_{0.5} \mathrm{Na}_{0.5} \mathrm{TiO}_{3}$ with $\mathrm{x} \geq 0.3 \mathrm{~mol}$ start to exhibit the relaxor ferroelectric properties[18]. $\left(\mathrm{Na}_{0.5}\right.$ $\left.\mathrm{Bi}_{0.5}\right)_{1-\mathrm{x}} \mathrm{Ba}_{\mathrm{x}} \mathrm{Zr}_{\mathrm{y}} \mathrm{Ti}_{1-\mathrm{y}} \mathrm{O}_{3}$, BNBZT is another most promising NBT based material posses rhombohedral - tetragonal phase with morphotropic phase boundary (MPB) at $\mathrm{x}=0.07-0.08$. The aim of this paper is to investigate the phase structure, microstructure, dielectric, complex impedance, electric modulus and conductivity behavior of $\left(\mathrm{Na}_{0.5} \mathrm{Bi}_{0.5}\right)_{1-\mathrm{x}} \mathrm{Ba}_{\mathrm{x}}$ $\mathrm{Zr}_{\mathrm{y}} \mathrm{Ti}_{1-\mathrm{y}} \mathrm{O}_{3}$ ( abbreviated as BNBZT) ceramics. NBT modified with barium at $\mathrm{A}$-site and zirconium at B-site, i.e., $\left(\mathrm{Na}_{0.5}\right.$ $\left.\mathrm{Bi}_{0.5}\right)_{1-\mathrm{x}} \mathrm{Ba}_{\mathrm{x}} \mathrm{Zr}_{\mathrm{y}} \mathrm{Ti}_{1-\mathrm{y}} \mathrm{O}_{3},(\mathrm{x}=0.10,0.12 ; \mathrm{y}=0.04)$, (abbreviated as $0.10 \mathrm{BNBZT}, 0.12 \mathrm{BNBZT}$ ). These are the promising candidates for device applications. We expect to provide an alternative direction for searching and developing high temperature lead-free relaxor ferroelectrics through this study. In addition, the mechanisms of the relaxor behavior in the BNBZT ceramics are discussed in detail.

\section{Experimental}

The BNBZT Ceramic samples were prepared by a conventional solid state sintering. AR grade powders of oxides or carbonates with $99 \%$ purity were used as the starting materials. These materials were grounded for $10 \mathrm{~h}$ and calcined at $850^{\circ} \mathrm{C} / 2 \mathrm{~h}$. After calcination, the grounded powders were pressed into disks with $12 \mathrm{~mm}$ diameter and about $2 \mathrm{~mm}$ in thickness. The disks were sintered at $1180^{\circ} \mathrm{C} / 3 \mathrm{hrs}$ in air.

The phase structure was examined using x-ray powder diffraction analysis using a Phillips diffractometer using $\mathrm{CuK} \alpha$ radiation wavelength, $\lambda=1.5406 \mathrm{~A}^{\circ}$ for wide range of bragg's angle, $2 \theta\left(10^{\circ} \leq 2 \theta \leq 70^{\circ} \mathrm{C}\right)$ with a scanning rate of $2^{0} / \mathrm{min}$. Lattice parameters have been calculated through POWD software. For the observation of the microstructure samples were polished and thermally etched. Finally, the microstructures were observed by scanning electron microscopy (SEM: JEOL_JY: Model 5800F).The permittivity $\left(\varepsilon^{*}\right)$, impedance $\left(Z^{*}\right)$, electrical modulus $\left(\mathrm{M}^{*}\right)$, and conductivity $\left(\sigma^{*}\right)$ as a function of temperature $\left(35-600^{\circ} \mathrm{C}\right)$ and frequency $(45 \mathrm{~Hz}$ to $5 \mathrm{MHz})$ were performed with computer interfaced LCR Hi-Tester (HIOKI 3532-50, japan).

\section{Results and Discussion}

\subsection{The Phase Structure of $\left(\mathrm{Na}_{0.5} \mathrm{Bi}_{0.5}\right)_{1-\mathrm{x}} \mathrm{Ba}_{\mathrm{x}} \mathrm{Zr}_{\mathrm{y}} \mathrm{Ti}_{1-\mathrm{y}} \mathrm{O}_{3}$, $(x=0.10,0.12 ; y=0.04)$, (Abbreviated as 0.10 BNBZT, 0.12 BNBZT) Ceramics}

Figure 1(a) shows that X-ray diffraction (XRD) patterns of $\left(\mathrm{Na}_{0.5} \mathrm{Bi}_{0.5}\right)_{1-\mathrm{x}} \mathrm{Ba}_{\mathrm{x}} \mathrm{Zr}_{\mathrm{y}} \mathrm{Ti}_{1-\mathrm{y}} \mathrm{O}_{3},(\mathrm{x}=0.10,0.12 ; \mathrm{y}=0.04)$ ceramics at room temperature. It is observed from the patterns; that all samples show pure perovskite phase and there is no traces of secondary phase. This indicates that both Barium and zirconium have completely diffused into NBT lattice to form new solid solution. The orthorhombic phase is characterized by $(202) /(020)$ peak splitting by about $45^{\circ}[6]$. The tetragonal phase is characterized by $(002) /(200)$ peak splitting by about $45^{\circ}[6]$. According to Figure 1(a), the phase structure of $0.10 \mathrm{BNBZT}, 0.12 \mathrm{BNBZT}$ ceramic is pure perovskite phase with tetragonal symmetry.

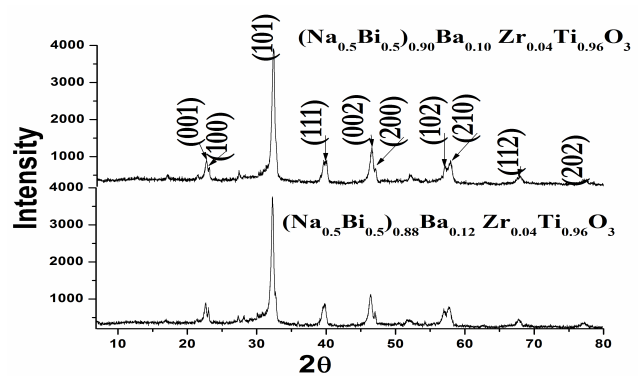

(a)

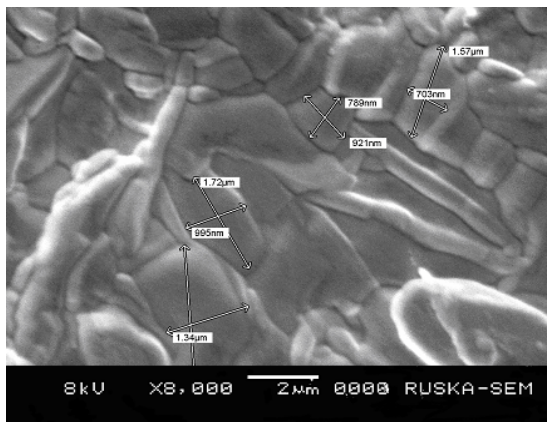

$0.10 \mathrm{BNBZT}$

(b)

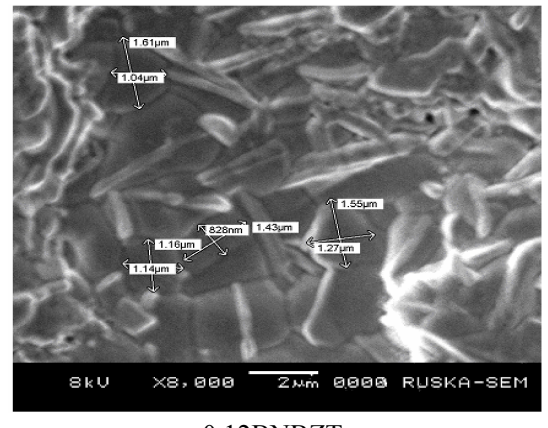

$0.12 \mathrm{BNBZT}$

(c)

Figure 1. XRD patterns and SEM micrographs (bars on the micrograph resembles the size of individual grain, the scale to measure the average grain size of the sample is $2 \mu \mathrm{m}$ for $0.10 \mathrm{BNBZT}$ and $0.12 \mathrm{BNBZT}$

Table 1. Lattice parameters

\begin{tabular}{|c|c|c|c|c|c|c|}
\hline Composition & \multicolumn{2}{|c|}{$\begin{array}{c}\text { Lattice pa- } \\
\text { rameters }(\AA)\end{array}$} & $\mathrm{c} / \mathrm{a}$ & $\mathrm{V}\left(\AA^{3}\right)$ & \multicolumn{2}{|c|}{$\begin{array}{c}\text { Density } \\
\left(\mathrm{gm} / \mathrm{Cm}^{3}\right)\end{array}$} \\
\hline & $\mathrm{a}$ & $\mathrm{c}$ & & & $\rho_{\operatorname{Exp}}$ & $\rho_{\text {cal }}$ \\
\hline $0.10 \mathrm{BNBZT}$ & 3.818 & 3.915 & 1.025 & 57.68 & 6.23 & 6.27 \\
\hline $0.12 \mathrm{BNBZT}$ & 3.841 & 3.942 & 1.026 & 58.19 & 5.76 & 6.16 \\
\hline
\end{tabular}

It is also observed that as Ba concentration increases, lattice parameters and cell volume increases. In the perovskite structure of $\left(\mathrm{Na}_{0.5} \mathrm{Bi}_{0.5}\right)_{1-\mathrm{x}} \mathrm{Ba}_{\mathrm{x}} \mathrm{Zr}_{\mathrm{y}} \mathrm{Ti}_{1-\mathrm{y}} \mathrm{O}_{3}$, the substitution of $\mathrm{Ba}^{2+}$ for $\mathrm{Na}^{+}$and $\mathrm{Bi}^{3+}$ on the A-site increases the crystal plane spaces and causes the increase of lattice constant and lattice distortion and ultimately causes the appearance of tetragonal ferroelectric phase at room temperature as shown in Table.1. The increase in lattice parameters and cell volume are also reported in PZT system[19]. The density of the sintered materials has been measured by Archimedes method. The 
Experimental density achieved above $90 \%$ to that of theoretical density, which is tabulated in table.1.

Figure 1 (b), (c) shows the microstructures on sintered BNBZT ceramics with different $\mathrm{x}$ content and at constant zirconium concentration. Grain shapes are clearly visible, indicating the existence of polycrystalline microstructure. Grains of unequal size appear to be distributed in the studied materials. The average grain size of the studied materials is estimated by line intercept method. Grain size for $0.10 \mathrm{BNBZT}$ is found to be $1.15 \mu \mathrm{m}$ and for $0.12 \mathrm{BNBZT}$ is found to be $1.29 \mu \mathrm{m}$. The average grain size is found to be increased with increase in Ba content.

\subsection{Dielectric Properties of $\left(\mathrm{Na}_{0.5} \mathrm{Bi}_{0.5}\right)_{1-\mathrm{x}} \mathrm{Ba}_{\mathrm{x}} \mathrm{ZryTi}_{1-\mathrm{y}} \mathrm{O}_{3}$ Ceramics}

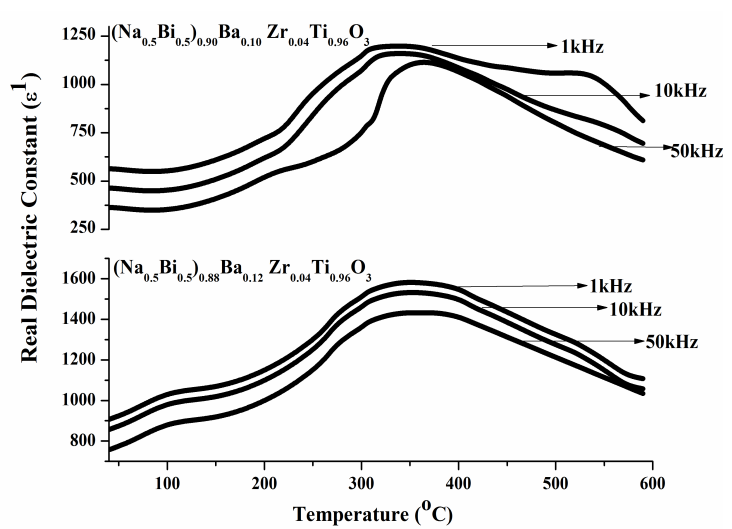

(a)

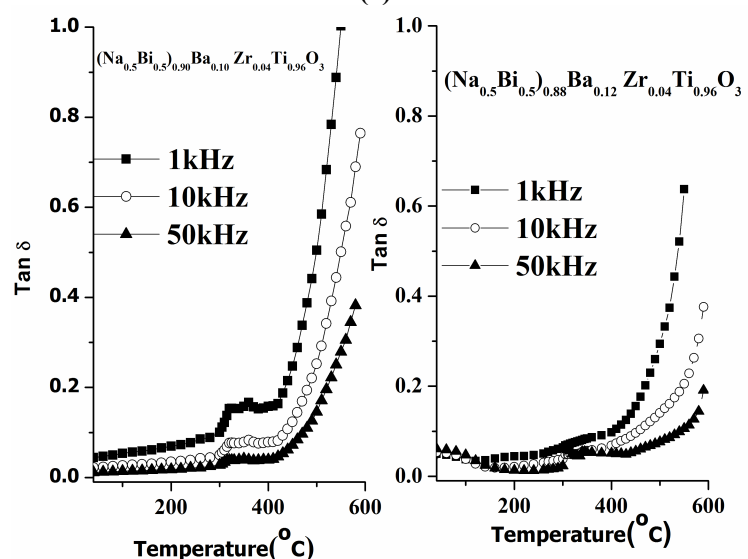

(b)

Figure 2. Temperature dependence of the dielectric constant and Tan $\delta$ for $0.10 \mathrm{BNBZT}$ and $0.12 \mathrm{BNBZT}$

Figure.2 (a) shows the temperature dependence of the dielectric permittivity $\left(\mathrm{Na}_{0.5} \mathrm{Bi}_{0.5}\right)_{1-\mathrm{x}} \mathrm{Ba}_{\mathrm{x}} \mathrm{ZryTi}_{1-\mathrm{y}} \mathrm{O}_{3}$ ceramics at a temperature range of $35^{\circ} \mathrm{C}-600^{\circ} \mathrm{C}$. For $0.10 \mathrm{BNBZT}$ and $0.12 \mathrm{BNBZT}$, the transition temperatures are shown in Table.2. It is observed that from Figure 2(a) that the $\mathrm{T}_{\mathrm{m}}$ increases from $343^{\circ} \mathrm{C}(0.10 \mathrm{BNBZT})$ to $360^{\circ} \mathrm{C}(0.12 \mathrm{BNBZT})$ ceramics with increase of Barium content; this result is consistent with the above XRD analysis, and the phase transition temperature range around $\mathrm{T}_{\mathrm{m}}$ become more and more broader with increasing addition of Barium, which can be called the diffuse phase transition. In addition, it can be observed that BNBZT ceramics show a broad dielectric peak with maximum permittivity maximum and low dielectric loss. This result may be used for high temperature applications.

A strong frequency dispersion of the dielectric permittivity is clearly seen for the samples for 0.10BNBZT and $0.12 \mathrm{BNBZT}$ (Figure 2(a)). It is believed that the diffuse phase transition and the frequency dispersion of dielectric permittivity are the two typical characteristics for the relaxor ferroelectrics. Therefore, it can be concluded that BNBZT ceramics are indeed lead-free relaxor ferroelectric. In addition to this Figure 2(b) show low dielectric loss in the temperature range $35^{\circ} \mathrm{C}$ to $400^{\circ} \mathrm{C}$.

Table 2. Dielectric Data (at $1 \mathrm{KHz})$

\begin{tabular}{|l|c|c|c|c|c|}
\hline Composition & $\begin{array}{c}\boldsymbol{T} \boldsymbol{m} \\
\boldsymbol{\rho} \boldsymbol{C})\end{array}$ & $\boldsymbol{\varepsilon}_{\boldsymbol{R} \boldsymbol{T}}$ & $\boldsymbol{\varepsilon}_{\boldsymbol{m}}$ & $\begin{array}{c}\text { Tan } \boldsymbol{\delta} \boldsymbol{a t} \\
\boldsymbol{R T}\end{array}$ & $\begin{array}{c}\boldsymbol{T a n} \boldsymbol{\delta} \text { at } \\
\boldsymbol{T}_{\boldsymbol{m}}\end{array}$ \\
\hline $0.10 \mathrm{BNBZT}$ & 343 & 559 & 1198 & 0.044 & 0.028 \\
\hline $0.12 \mathrm{BNBZT}$ & 360 & 751 & 1481 & 0.049 & 0.084 \\
\hline
\end{tabular}

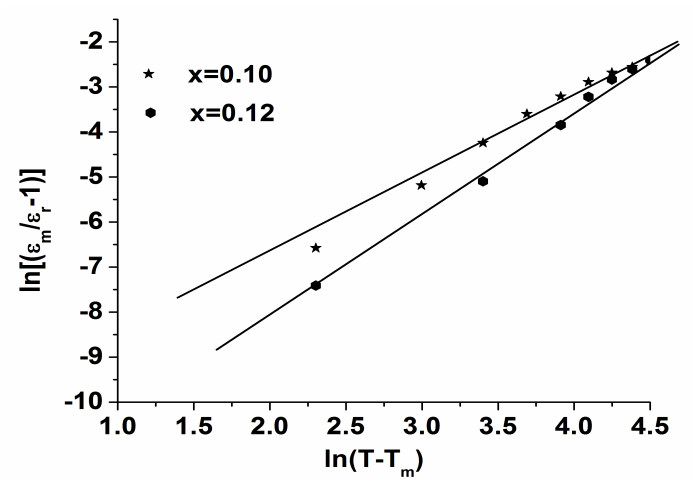

Figure 3. $\ln \left[\left(\varepsilon_{\mathrm{m}} / \varepsilon_{\mathrm{r}}-1\right)\right] \mathrm{Vs} \ln \left(\mathrm{T}-\mathrm{T}_{\mathrm{m}}\right)$ at $1 \mathrm{kHz}$

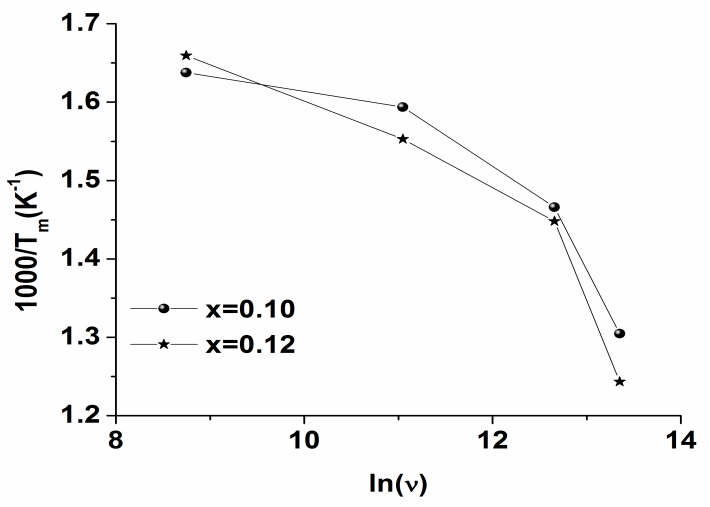

Figure 4. Verifying Vogel-Fulcher Relation

\subsection{Relaxor Behavior of $\left(\mathrm{Na}_{0.5} \mathrm{Bi}_{0.5}\right)_{1-\mathrm{x}} \mathrm{Ba}_{\mathrm{x}} \mathrm{ZryTi}_{1-\mathrm{y}} \mathrm{O}_{3}$ Ceramics}

It is well known that the dielectric permittivity of a normal ferroelectric should obey the Curie-Weiss law when the temperature exceeds the Curie temperature,

$$
\varepsilon=\frac{C}{T-T_{C W}}
$$

Where $\mathrm{C}$ is the Curie-Weiss Constant and $\mathrm{T}_{\mathrm{CW}}$ is the Curie Weiss temperature. The Curie Weiss Constant $\mathrm{C}$ reflects the 
nature of the ferroelectric transition.

For the relaxor ferroelectrics, the reciprocal of the dielectric constant and temperature obeys modified Curie-Wiess law

$$
\frac{1}{\varepsilon}-\frac{1}{\varepsilon_{m}}=\frac{\left(T-T_{m}\right)^{\gamma}}{C}
$$

Where $\mathrm{C}$ is the Curie constant, $\gamma$ is called a diffusion coefficient ranging from 1 (a normal ferroelectric) to 2 (an ideal relaxor ferroelectric). In order to further confirm the effect Barium and Zirconium content on the diffuse phase transition behavior of BNBZT ceramics, the plot of $\ln \left[\left(\varepsilon_{\mathrm{m}} / \varepsilon_{\mathrm{r}}-1\right)\right]$ Vs $\ln \left(\mathrm{T}-\mathrm{T}_{\mathrm{m}}\right)$ at $1 \mathrm{kHz}$ for 0.10 and $0.12 \mathrm{BNBZT}$ ceramics are shown in Figure 3.

A Linear relationship is observed for both specimens. The slope of the fitting curves is used to determine the $\gamma$ value. The value of $\gamma$ at $1 \mathrm{kHz}$ are found to be 2 for $0.10 \mathrm{BNBZT}$ and 1.67 for $0.12 \mathrm{BNBZT}$ indicating transitions are of diffusive in nature. The values of the $\gamma$ indicate that the compositions are highly disordered.

The relaxation behavior in relaxor ferroelectrics can be explained by many theory model such as composition fluctuation theory, super paraelectricity theory, the merging of micropolar regions into macropolar regions and random field model.[1, 4, 20] The common point of these models is based on the local distortion of the crystal structure, giving rise to polar nano regions (PNRs). In BNBZT system $\mathrm{Ba}^{2+}$ and $\mathrm{Zr}^{4+}$ occupies A-site and B-site of $\mathrm{ABO}_{3}$ perovskite structure because of their large ionic radius. In BNBZT in A-site $\mathrm{Na}$, $\mathrm{Bi}$ and $\mathrm{Ba}$ have different valences and ionic radii, which results in the formation of the local electric fields owing to the local charge imbalance and the local elastic fields due to local structure distortions. This similar phenomenon also occurs at the $\mathrm{B}$-site of the $\mathrm{ABO}_{3}$ perovskite structure. The presence of the random field, including the local electric fields and elastic field hinders the long range dipole alignment, i.e., giving rise to PNRs. These PNRs are isolated and frustrated in BNBZT system and are embedded in the disordered matrix, which results in the relaxor behviour. Consequenstly, the relaxor behavior of BNBZT ceramics is believed to result from the complex response of all the PNRs and matrices.

In relaxor materials, an empirical Vogel-Fulcher (VF) relationship can be used to account for the dielectric relaxation nature[21]. The dielectric relaxation appears as a result from thermally activated polarization between two equivalent variants. Based on this model, the polarization flipping frequency $v_{0}$ is related to the activation energy $E_{a}$ (the barrier between two equivalent polarization states) as follows

$$
v=v_{0} \exp \left[\frac{-E_{a}}{K_{B}\left(T_{m}-T_{f}\right)}\right]
$$

Where $v, v_{0}, \mathrm{~K}_{\mathrm{B}}$ and $\mathrm{E}_{\mathrm{a}}$ are respectively the operating frequency, pre-exponential factor, Boltzmann constant and the activation energy. $\mathrm{T}_{f}$ is the freezing frequency. $\mathrm{T}_{f}$ is regarded as the temperature where the dynamic reorientation of the dipolar cluster polarization can no longer be thermally activated.

Figure 4 shows the temperature dependence of the relaxation frequency for 0.10BNBZT and 0.12BNBZT, analysis based on the VF model yielded $\mathrm{T}_{f}=273^{\circ} \mathrm{C}, \mathrm{E}_{\mathrm{a}}=$ $0.0346 \mathrm{eV}$, and $v_{0}=4.60 \times 10^{9} \mathrm{~Hz}$ for $0.10 \mathrm{BNBZT}$; $\mathrm{T}_{f}=$ $258^{\circ} \mathrm{C}, \mathrm{E}_{\mathrm{a}}=0.007 \mathrm{eV}$, and $v_{0}=5.03 \times 10^{8} \mathrm{~Hz}$ for $0.12 \mathrm{BNBZT}$, which provides the evidence of the relaxor behavior in BNBZT ceramics.

The relaxor behavior as observed in studied materials can be induced by many reasons such as microscopic compositions fluctuation, the merging of micropolar regions into macropolar regions, or a coupling of ordered parameter and local disorder mode through the local strain. Vugmeister and Glinichuk reported[22] that the randomly distributed electrical field of strain field in a mixed oxide system is the main reason leading to the relaxor behaviour. In the present compositions $\left(\mathrm{Na}_{0.5} \mathrm{Bi}_{0.5}\right)_{1-\mathrm{x}} \mathrm{Ba}_{\mathrm{x}} \mathrm{Zr}_{\mathrm{y}} \mathrm{Ti}_{1-\mathrm{y}} \mathrm{O}_{3}, \mathrm{Na}, \mathrm{Ba}$ and $\mathrm{Bi}$ ions occupy the $\mathrm{A}$-site of the $\mathrm{ABO}_{3}$ perovskite type structure and $\mathrm{Zr}$ and Ti ions occupy the B-site. As known Ti and $\mathrm{Zr}$ are ferroelectrically active and these cations are off-centered in the octahedral site gives rise to a local dipolar moment. In perovskite type compounds the relaxor behavior appears when at least two cations occupy the same crystallographic site $\mathrm{A}$ or $\mathrm{B}$. The ionic radius of $\mathrm{Zr}^{4+}(0.79 \AA)$ is larger than that of $\mathrm{Ti}^{4+}(0.68 \AA)$. Therefore, an inhomogeneous distribution results at the B-site of the structure. A cationic disorder induced by B-site substitution is always regarded as the main derivation of relaxor behavior. However, the occurrence of relaxation in the compositions attributed to the existence of a nano-polar region[23].

\subsection{Impedance and electrical Modulus analysis}

The electrical behaviour of the compound has been studied over a range of temperature and frequency using the ac technique of complex impedance spectroscopy (CIS). This technique enables us to separate the real and imaginary components of the electrical parameters and hence provides a true picture of the material properties. Each representation can be used to high light a particular aspect of the response of a sample. Figure 5(a) shows the variation of the real part of the impedance $\left(Z^{1}\right)$ as a function of frequency at various temperatures for $0.10 \mathrm{BNBZT}$. It is observed that the magnitude of $Z^{1}$ decreases with the increase of frequency and temperature, indicating an increase in ac conductivity. The merging of $Z^{1}$ curves at all temperatures above $10 \mathrm{kHz}$ is ascribed to be the release of space charges as a result of reduction in the barrier properties. This may be due to the enhancement of ac conductivity of material with temperature at higher frequencies. Similar behaviour has been observed in the composition for 0.12BNBZT.

Figure 5(b) shows the variation of imaginary part of impedance $Z^{11}$ as a function of frequency at different temperatures for 0.10BNBZT. At low temperatures (below $\left.300^{\circ} \mathrm{C}\right), \mathrm{Z}^{11}$ decreased monotonically, suggesting that relaxation is absent in the measured frequencies. This means 
that the relaxation species in the material are immobile species/ electrons and orientation effects may be involved in the sample. Above $300^{\circ} \mathrm{C}$, the nature of the $\mathrm{Z}^{11}$ starts attains a maximum value at a particular frequency and the peak position varies with temperature which indicated the defects or the vacancies appearance at a high temperature.

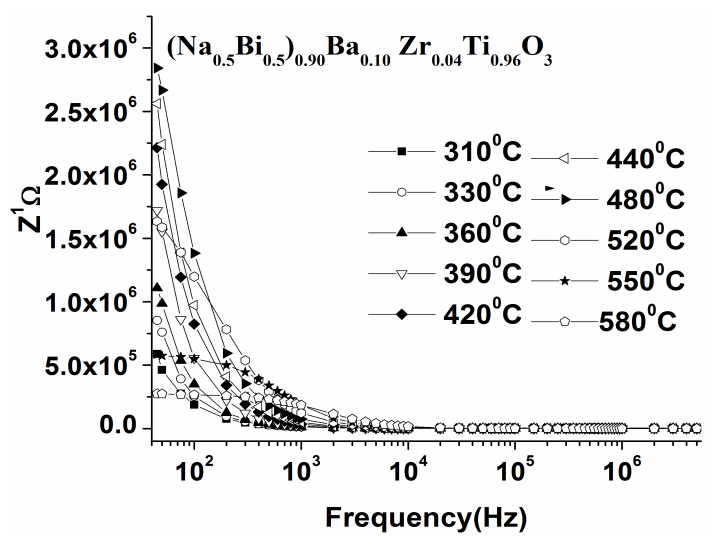

(a)

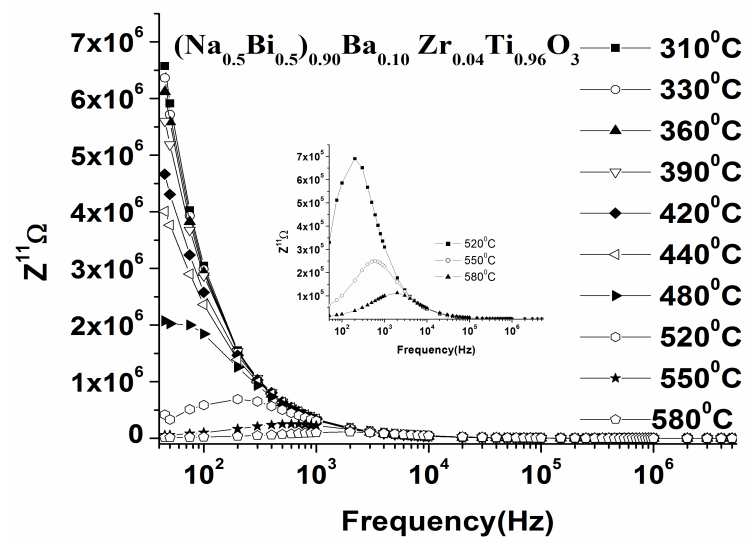

(b)

Figure 5. Variation of the $Z^{1}$ and $Z^{11}$ with frequency at different temperatures for 0.10BNBZT

The asymmetric variation in the broadness of the $\mathrm{Z}^{11}$ peak suggested an electrical process with a spread of the relaxation time. This variation shows considerable decrement in the magnitude of $Z^{11}$ with a shift towards the higher side as temperature increases. The shifting of $Z^{11}$ maximum towards a higher frequency side explains the presence of temperature dependent on the relaxation phenomenon. The decrement in the magnitude of $Z^{11}$ with temperature indicates more conductivity due to the space charge in the material. Therefore, the temperature dependent electrical relaxation phenomenon exists in the studied materials[24]. Also, it is obvious from the Figure 5(b) that the merging of $Z^{11}$ values at high frequency region is an indication of the accumulation of space charge in the material. The same trend of $Z^{11}$ has been observed in 0.12BNBZT.

The normalized imaginary part $\left(Z^{11} / Z^{11}{ }_{\max }\right)$ of impedance as a function of frequency at several temperatures for $0.10 B N B Z T$ has been shown in Figure 6. The $\mathrm{Z}^{11} / \mathrm{Z}^{11}{ }_{\max }$ parameter exhibited a peak of slightly asymmetric degree at each temperature indicating the triggering of another re- laxation process.

At the peak, the relaxation is defined by the condition $\omega_{\mathrm{m}} \tau_{\mathrm{m}}=1$, where, $\tau_{\mathrm{m}}$ is relaxation time at the peak. This same trend has also been observed in 0.12BNBZT. The relaxation frequency obeys the Arrhenius relation given by

$$
\omega_{\mathrm{m}}=\omega_{\mathrm{o}} \exp \left[-\mathrm{E}_{\mathrm{r}} / \mathrm{K}_{\mathrm{B}} \mathrm{T}\right]
$$

where, $\omega_{0}$ is pre exponential factor, and the activation energies (Figure 7a) for 0.10BNBZT and 0.12BNBZT(results for the 0.12BNBZT ceramic show similar and omitted for briefness) are evaluated and are found to be $\mathrm{E}_{\mathrm{a}}=0.67 \mathrm{eV}$ and for $0.12 \mathrm{BNBZT}, \mathrm{E}_{\mathrm{a}}=0.63 \mathrm{eV}$.

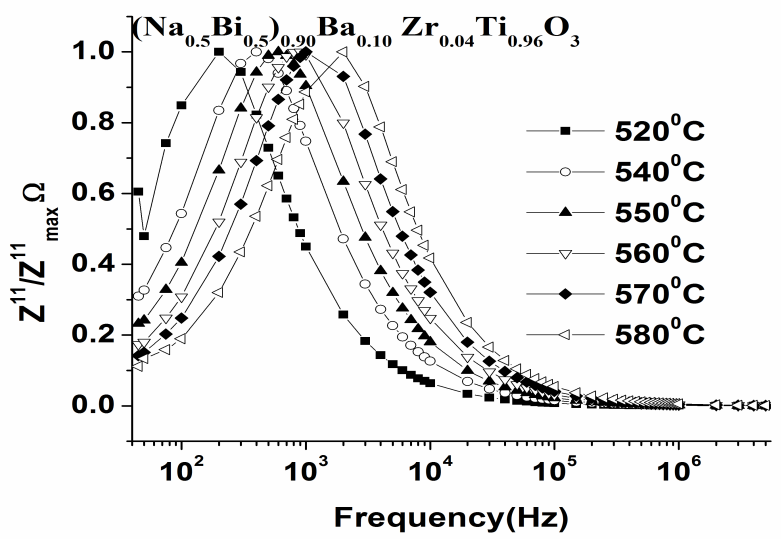

Figure 6. Variation of normalized imaginary part of the impedance $\left(\mathrm{Z}^{11} / \mathrm{Z}^{11}{ }_{\max }\right)$ as a function of frequency at different temperatures for $0.10 \mathrm{BNBZT}$

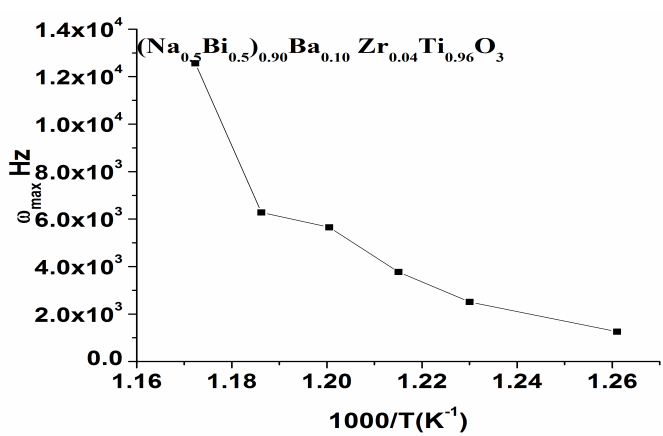

(a)

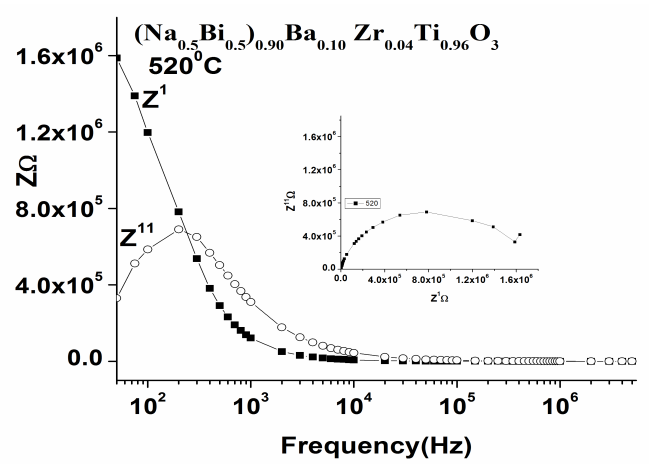

(b)

Figure 7. $a$ : Arrhenius plot of $Z^{11}$ peak frequencies for 0.10BNBZT; $b$ : Frequency dependence of $Z^{1}$ and $Z^{11}$, corresponding Argand diagram(insert) for $0.10 \mathrm{BNBZT}$

Figure 7 (b) shows the frequency dependence of $Z^{1}$ and $\mathrm{Z}^{11}$ at different temperatures and Argand diagram typically 
drawn at $520^{\circ} \mathrm{C}, 560^{\circ} \mathrm{C}$ for $0.10 \mathrm{BNBZT}$, this type of plot indicating the existence of impedance relaxation phenomena.

In Figure 8, the impedance data of 0.10BNBZT (results for the 0.12BNBZT ceramic show similar and omitted for briefness), are represented in Nyquist diagrams (the imaginary part $Z^{11}$ Vs real part $Z^{1}$ of complex impedance for several representative temperature). At lower temperatures, from RT to temperature near above the ferroparaelectric transition temperature at around $350^{\circ} \mathrm{C}$, the shape of the plots tends to a straight line with a large slope indicating insulating behaviour of the samples. This effect is more pronounced for the BNBZT ceramics where the morphological features make the grain boundary contributions almost negligible. As the temperature increase above the $350^{\circ} \mathrm{C}$, the slope of the curves decreases, bowing down towards the real axis. At temperature above $450^{\circ} \mathrm{C}$ a tendency to a semicircular behaviour is observed, indicative of the presence of both localized and non localized conduction processes.

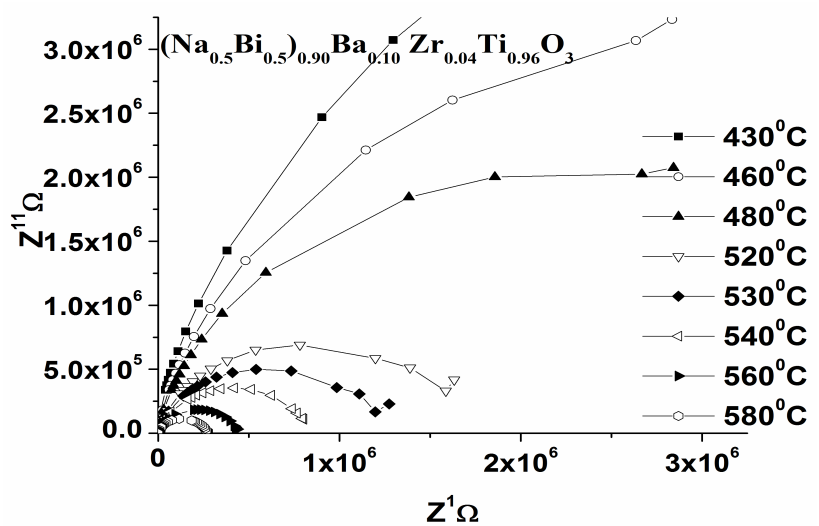

Figure 8. Complex impedance plots (z11VsZ1) at several temperature of $0.10 \mathrm{BNBZT}$ (a similar behaviour was found for $0.12 \mathrm{BNBZT}$ )

It is also observed that, the reduction of grain $\left(\mathrm{R}_{\mathrm{g}}\right)$, grain boundary $\left(\mathrm{R}_{\mathrm{gb}}\right)$ resistance and negative temperatures coefficient of resistance (NTCR) behaviour like semi conducting materials $[25,26]$. At higher temperatures, the Cole-Cole plots are resolved into two overlapping arcs suggests the contribution of two relaxation mechanisms due to grain and grain boundary. The observed behaviour in the studied compositions (0.10BNBZT and 0.12BNBZT) indicates the conduction is predominant through grain boundary and giving a scope for variety of device applications.

\section{Electrical Modulus}

The electrical modulus (M) response corresponds to the relaxation of the electrical field in the material when the electrical displacement remains constant. Therefore, the modulus represents the real dielectric relaxation process[27]. The usefulness of the modulus representation in the analysis of relaxation properties was demonstrated both for ionic conductors[28] and polycrystalline ceramics[29]. In practice, regions of low capacitance, such as grain interiors, are characterized using imaginary part of electrical modulus, $\mathrm{M}^{11}$ data, where as more resistive regions, such as grain boundaries and pellet surface layers, which are often have higher associated capacitances, are characterized using imaginary part of impedance $Z^{11}$ spectra. The complex electrical modulus can be expressed in terms of permittivity as

$$
\begin{gathered}
\varepsilon^{*=} \varepsilon^{1}-\mathrm{i}^{11} \\
\mathrm{M}^{*}(\omega)=1 / \varepsilon^{*=} \mathrm{M}^{1}(\omega)+\mathrm{i} \mathrm{M}^{11}(\omega) \\
=\left(\varepsilon^{1}+\mathrm{i} \varepsilon^{11}\right) /\left(\varepsilon^{12}+i \varepsilon^{112}\right)
\end{gathered}
$$

Figure $9(a, b)$ shows the frequency dependence of real $\left(M^{1}\right)$ and imaginary $\left(\mathrm{M}^{11}\right)$ part of modulus at different temperatures. From Figure $9 \mathrm{a}, \mathrm{M}^{1}$ increases with increase in frequency and almost takes nearly a constant value beyond 10 $\mathrm{kHz}$. At low frequency and high temperature region, $\mathrm{M}^{1}$ approaches zero confirming an appreciable electrode and /or ionic polarization[29].

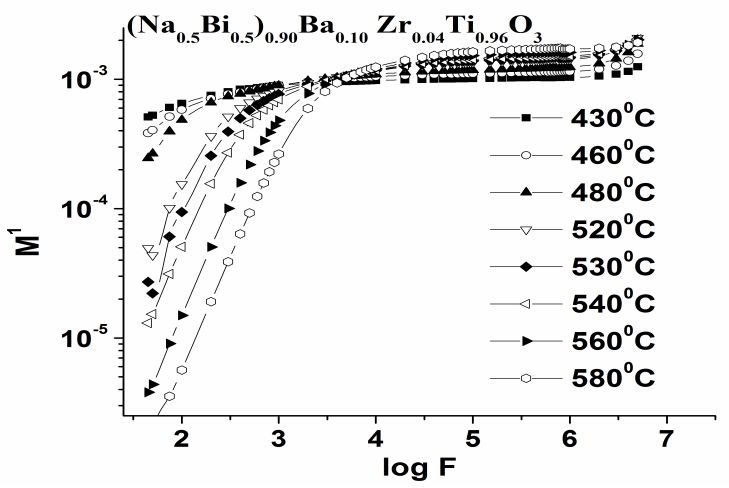

(a)

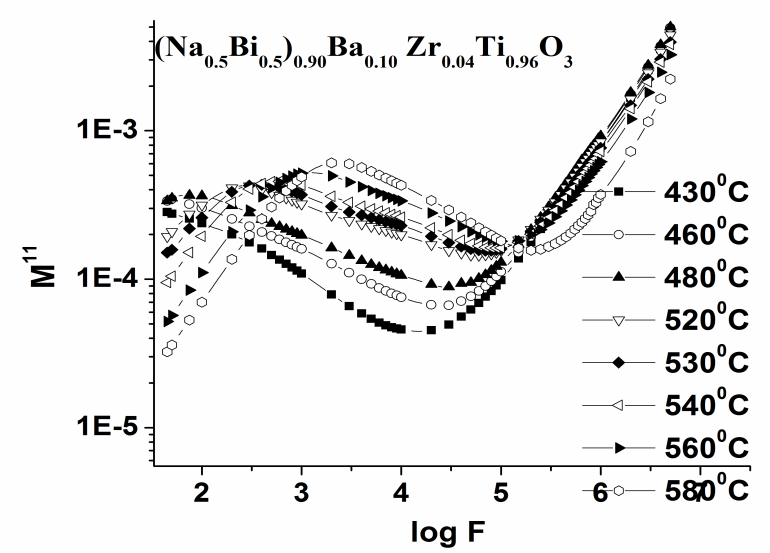

(b)

Figure 9. Variation of $\mathrm{M}^{1}$ and $\mathrm{M}^{11}$ with frequency for $0.10 \mathrm{BNBZT}$

It is observed form the Figure $9 \mathrm{~b}$ that a peak at certain frequency (i.e., $10 \mathrm{kHz}$ ) regime at high temperature $\left(400^{\circ} \mathrm{C}-580^{\circ} \mathrm{C}\right.$ ) for $0.10 \mathrm{BNBZT}$ (results for the $0.12 \mathrm{BNBZT}$ ceramic show similar and omitted for briefness). It is also evident that the magnitude of $\mathrm{M}^{11}$ in the high frequency region increase with increase in temperature. The appearance of $\mathrm{M}^{11}$ peaks at a characteristic frequency $\left(\omega_{\max }\right)$ is dependent on temperature and can be related to the type and strength of the electrical relaxation phenomenon in the materials. The observed peaks appear to be shifting towards higher frequency side with rise in temperature, possibly due to decreasing relaxation time in the materials. All the curves at different temperatures in the higher frequency regime appeared to be merged with one another. Merging of all $\mathrm{M}^{11} \mathrm{Vs}$ $\log \mathrm{F}$ curves at high frequencies indicates disappearance of 
space charge polarization. The width of peaks increases with decrease of temperature is observed. This type of temperature and frequency dependence of $\mathrm{M}^{11}$ arises due to the distribution of relaxation times in the material because of cationic disorder at both A-and B-sites in this composition. Similar behaviour has been noticed in both $\mathrm{M}^{1}, \mathrm{M}^{11} \mathrm{Vs} \log \mathrm{F}$ in the composition for 0.12BNBZT

It is well known that thermal fluctuations are dominant over the dipolar/polar cluster interaction at temperatures of several orders of magnitude greater than $T_{m}$. At such very high temperatures the interaction among the dipoles /polar clusters can be treated a negligible and hence, the temperature dependence of angular frequency can be well described by Arrhenius relation.

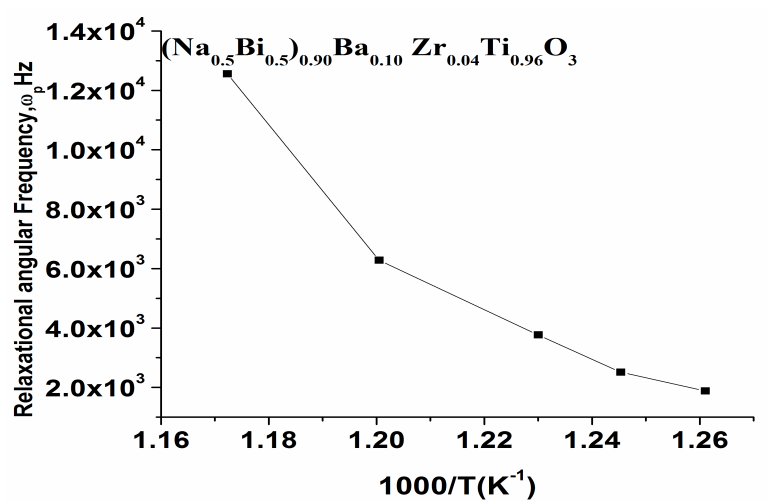

(a)

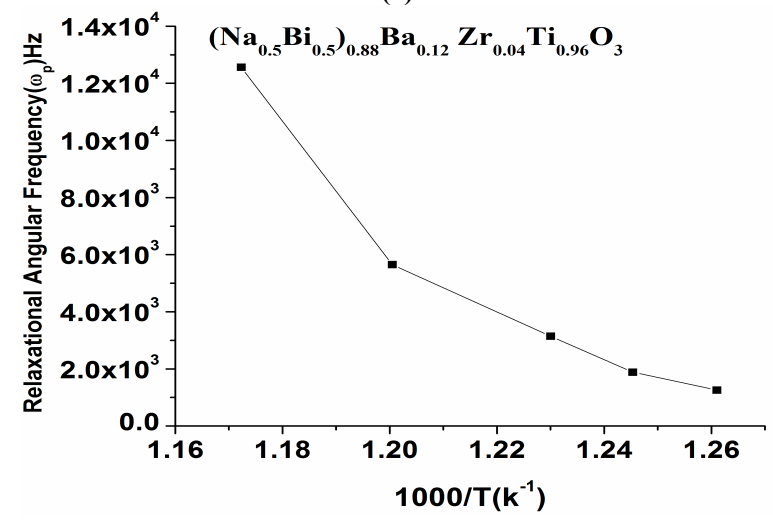

(b)

Figure 10. $\mathrm{M}^{\prime \prime}$-Peak frequency showing Arrhenius behavior for $0.10 \mathrm{BNBZT}$ and $0.12 \mathrm{BNBZT}$

The characteristic relaxation time, $\omega_{\max }{ }^{-1}=\left(2 \pi f_{\max }\right)^{-1}$ estimated from the $\mathrm{M}^{11}$ peak frequency represent the time scale of transition from long range mobility of charge carriers, and it is clearly a thermally activated process. From $\mathrm{M}^{11}$ peak frequencies, the relaxational activation energies are estimated, and are found to obey Arrhenius relation.

$$
\omega_{\mathrm{p}}=\omega_{\mathrm{o}} \exp \left[-\mathrm{E}_{\mathrm{\mu}} / \mathrm{KT}\right]
$$

Figure 10(a),(b) shows the Arrhenius behaviour in the materials, the activation energy values are computed and are found to be $0.83 \mathrm{eV}$ for $\mathrm{x}=0.10$ and $1.03 \mathrm{eV}$ for $\mathrm{x}=0.12$ respectively.

\subsection{Conductivity}

Figure 11(a) shows the electrical conductivity $\sigma(\omega)$ as a function of frequency at different temperatures for $0.10 \mathrm{BNBZT}$ (results for the 0.12BNBZT ceramic show similar and omitted for briefness). In the present materials, the ac conductivity is found to increase with increase in frequency suggesting the bound carriers trapped in the sample. Conductivity varying at lower frequencies corresponds to space charge polarization[30]. Also, a change in slope has been observed at a particular frequency is related to ion hopping frequency[31-33]. This trend represents the conductivity in the present materials for $0.10 \mathrm{BNBZT}$ and 0.12BNBZT obeys Jonscher law[34],

$$
\sigma(\omega)=\sigma_{\mathrm{dc}}+\mathrm{A} \omega^{\mathrm{n}}
$$

where $\sigma_{\mathrm{dc}}$ is frequency independent conductivity, the coefficient $\mathrm{A}$ and the frequency exponent $\mathrm{n}$ are thermally activated material dependent quantities. The term $A \omega^{\mathrm{n}}$ contains ac dependence and characterizes all dispersion phenomenons.

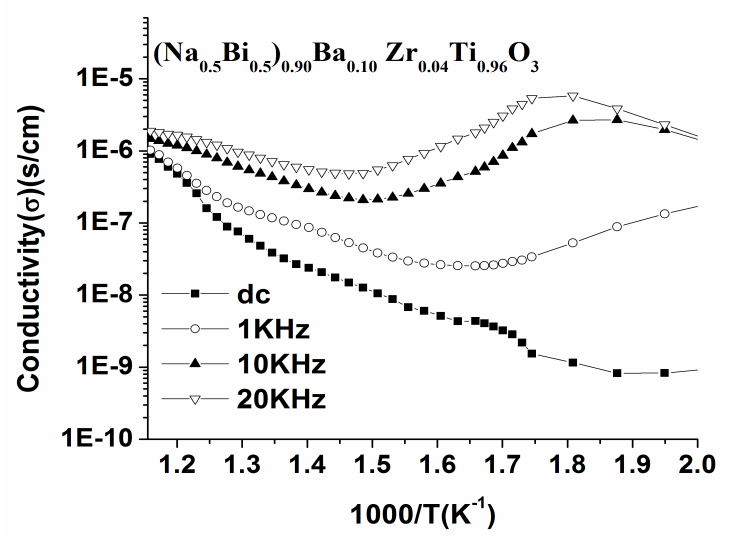

(a)

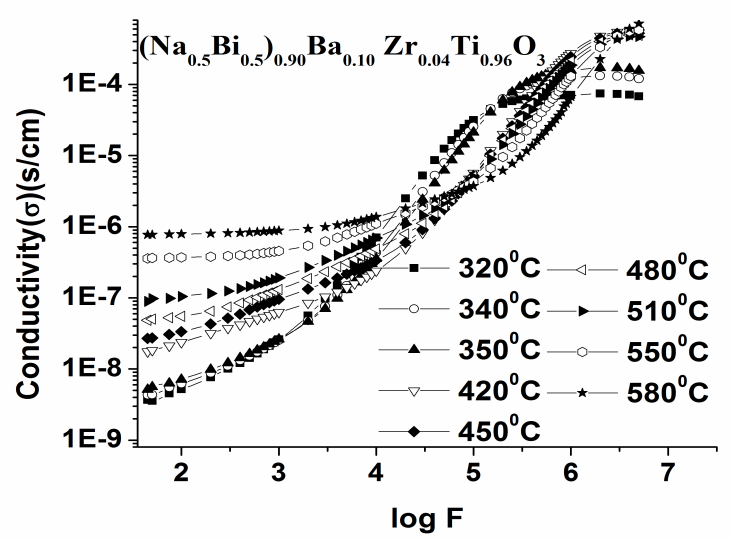

(b)

Figure 11. a: Frequency dependence of conductivity; b: Arrhenius plot of conductivity for $\mathrm{x}=0.10$

Figure $11 \mathrm{~b}$ shows the variation of conductivity $\left(\sigma_{\mathrm{dc}}\right.$ and $\left.\sigma_{\mathrm{ac}}\right)$ with inverse of temperature at different frequencies for $0.10 \mathrm{BNBZT}$. In low temperature region $\left(300^{\circ} \mathrm{C}-400^{\circ} \mathrm{C}\right)$, the conductivity showed dispersion, while, curves are merged at high temperatures region, revealing predominance of an onset of intrinsic conductivity mechanism. Similar behaviour in $\sigma$ Vs $1000 / T$ has been noticed in the composition for $0.12 \mathrm{BNBZT}$. The activation energies of ac and dc conductivity in the materials have been evaluated on the studied 
materials is given in Table. 3 .

The ac conductivity activation energies are found to increase with increase in temperature. The low values of activation energies may be due to the carrier transport through hopping between localized states in disordered manner. The conduction at higher temperatures might be due to oxygen vacancies and the conductivity in present materials is thermally activated.

Table 3. Activation energies of dc and ac conductivity

\begin{tabular}{|c|c|c|c|c|}
\hline Composition & \multicolumn{4}{|c|}{$0.10 \mathrm{BNBZT}$} \\
\hline \multirow{4}{*}{$\begin{array}{l}\text { Temperature } \\
\text { Range }\left({ }^{\mathrm{O}} \mathrm{C}\right)\end{array}$} & \multirow{3}{*}{\multicolumn{4}{|c|}{$\begin{array}{c}\text { Conductivity } \\
\text { Activation Energy }(\mathrm{eV}) \\
\text { ac }\end{array}$}} \\
\hline & & & & \\
\hline & & & & \\
\hline & $\mathrm{dc}$ & $1 \mathrm{kHz}$ & $10 \mathrm{kHz}$ & $20 \mathrm{kHz}$ \\
\hline $310-370$ & 0.19 & 0.21 & 0.17 & 0.18 \\
\hline $400-490$ & 0.33 & 0.25 & 0.28 & 0.29 \\
\hline $520-596$ & 0.73 & 0.51 & 0.69 & 0.37 \\
\hline Composition & \multicolumn{4}{|c|}{$0.12 \mathrm{BNBZT}$} \\
\hline \multirow{4}{*}{$\begin{array}{c}\text { Temperature } \\
\text { Range }\left({ }^{\circ} \mathrm{C}\right)\end{array}$} & \multirow{3}{*}{\multicolumn{4}{|c|}{$\begin{array}{c}\text { Conductivity } \\
\text { Activation Energy }(\mathrm{eV}) \\
\text { ac }\end{array}$}} \\
\hline & & & & \\
\hline & & & & \\
\hline & $\mathrm{dc}$ & $1 \mathrm{kHz}$ & $10 \mathrm{kHz}$ & $20 \mathrm{kHz}$ \\
\hline $100-200$ & 0.54 & 0.01 & 0.02 & 0.05 \\
\hline $240-380$ & 0.59 & 0.08 & 0.07 & 0.10 \\
\hline $440-580$ & 0.64 & 0.32 & 0.10 & 0.15 \\
\hline
\end{tabular}

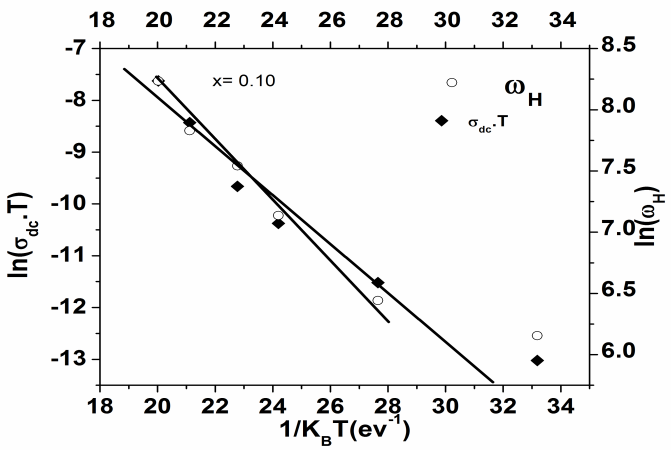

Figure 12. Arrhenius dependence of dc conductivity $\left(\sigma_{\mathrm{dc}}\right)$ and the hopping frequency $(\omega \mathrm{Hz})$ for $0.10 \mathrm{BNBZT}$

The temperature dependence of the dc conductivity and the hopping frequency follows the Arrhenius behaviour expressed by the following equations

$$
\begin{gathered}
\sigma_{d c}=\sigma_{0} \exp \left(\frac{-U_{d c}}{K_{B} T}\right) \\
\omega_{H}=\omega_{0} \exp \left(\frac{-U_{H}}{K_{B} T}\right)
\end{gathered}
$$

where, $\mathrm{U}_{\mathrm{dc}}$ and $\mathrm{U}_{\mathrm{H}}$ are the activation energies of the $\mathrm{dc}$ conductivity and the hopping frequencies of the carriers respectively, $\sigma_{\mathrm{o}}, \omega_{\mathrm{o}}$ are pre-exponential factors.

The activation energies (Figure.12) of $\mathrm{U}_{\mathrm{dc}}$ and $\mathrm{U}_{\mathrm{H}}$ are estimated to be $0.47 \mathrm{eV}, 0.23 \mathrm{eV}$ for $0.10 \mathrm{BNBZT}$ and $0.51 \mathrm{eV}$, $0.25 \mathrm{eV}$ for $0.12 \mathrm{BNBZT}$ respectively.

The value of activation energies again allowed us to confirm that the oxygen vacancies are dominant charge carriers in the present materials. Further, it is expected that sponta- neous polarization originating from the off center displacement of $\mathrm{Ti}^{4+}$ ions from the anionic charge center of the oxygen octahedron for the ceramic phase [35,36] which dominates the dielectric response of the material[37]. The presence of oxygen vacancies would distort the actual ionic dipoles due to the $\mathrm{Ti}^{4+}$ ions. The decay of polarizations due to distorted ionic dipoles could be the cause for the dielectric relaxation process. Thus, the relaxation process for the studied materials (0.10BNBZT and 0.12BNBZT) is attributed to the decay of polarization in the oxygen defect-related dipoles due to their hopping conduction.

\section{Conclusions}

Perovskite type $\left(\mathrm{Na}_{0.5} \quad \mathrm{Bi}_{0.5}\right)_{1-\mathrm{x}} \mathrm{Ba}_{\mathrm{x}} \mathrm{Zr}_{\mathrm{y}} \mathrm{Ti}_{1-\mathrm{y}} \mathrm{O}_{3}$ (BNBZT) (with $\mathrm{x}=0.10,0.12$ and $\mathrm{y}=0.04$ ) ceramics have been prepared through conventional solid-state sintering. At room temperature, XRD studies suggest that the studied compositions have single phase with tetragonal structure. As Ba concentration increases keeping $\mathrm{Zr}$ concentration constant lattice parameters and cell volume are found to increase. Microstructure studies reveal that the studied compositions are highly dense with a polycrystalline nature. Dielectric studies ( $\varepsilon^{1}$ Vs temperature) at various frequencies exhibit a peak broadening with diffused phase transition. It is observed that transition temperature $\left(\mathrm{T}_{\mathrm{m}}\right)$ shifted towards higher temperatures accompanied by a decrease in the magnitude of the dielectric maximum $\left(\varepsilon_{\mathrm{m}}\right)$ reveals a relaxor type nature. The values of the diffuseness parameter $\gamma=2$ for $\mathrm{x}=0.10$ and 1.67 for $\mathrm{x}=0.12$, obtained from the fit of a modified Curie-Weiss law established the relaxor type nature. Frequency dependence of maximum permittivity of the studied compositions has been modelled by using Vogel-Fulcher relation., the observed values are activation energy $\left(E_{a}\right)$, freezing temperature $\left(T_{f}\right)$ and operating frequency $\left(v_{\mathrm{o}}\right)$, Where $\mathrm{T}_{f}=273^{0} \mathrm{C}$, $\mathrm{Ea}=0.0346 \mathrm{eV}$, and $v_{0}=4.60 \times 10^{9} \mathrm{~Hz}$ for $\mathrm{x}=0.10 ; \mathrm{T}_{f}=$ $258^{\circ} \mathrm{C}, \mathrm{Ea}=0.007 \mathrm{eV}$, and $v_{0}=5.03 \times 10^{8} \mathrm{~Hz}$ for $\mathrm{x}=0.12$, which provides the evidence of the relaxor behavior in BNBZT ceramics. Variations of $Z^{1} / Z^{11}$ with frequency at different temperature are found to merge above $10 \mathrm{kHz}$ in both materials revealing the reduction in space charge polarization. In electrical modulus, real part of electrical modulus $\left(\mathrm{M}^{1}\right)$ with frequency at high temperature, it is observed that $\mathrm{M}^{1}$ tends to zero, confirms the electrode and/or ionic polarization. The low and high frequency side of imaginary Part of electrical Modulus i.e., $\mathrm{M}^{11}$ curves, $\left(\mathrm{M}^{11}\right.$ $\mathrm{Vs}$ F) represents hopping of ions and localized motion respectively in studied BNBZT compositions. The observed dispersion in $\sigma(\omega)$ at low frequencies is due to the electrode polarization. It is also observed that at low frequency, high temperature region reveals the transition from long range hopping to short range ion motion and conductivity relaxation phenomena.

\section{ACKNOWLEDGEMENTS}


The authors thank to Naval Science and Technology Laboratory (NSTL), Govt of India, Visakhapatnam, for funding the research project and University Grants commission, Govt of India for Research fellowship.

\section{REFERENCES}

[1] L. E. Cross, Ferroelectrics., 76 (1987) 241-67 and reference therein

[2] L. E. Cross, Ferroelectrics., 151 (1994) 305-20 and reference therein

[3] Z-G Ye, Key Engineering Materials., 155-156(1998) 81-122,

[4] Chen, I. W., J. Phys. Chem. Solids., 61(2000) 197-208

[5] L. E. Cross, Nature (London), 432(2004) 24-25

[6] M. Kosec, V. Bobnar, M. Hrovat, J. Bernard, B. Malic, and J. Holc, J. Mater. Res., 19(6) (2004) 1849-54

[7] M. D. Maeder, D. Damjanovic, N. Setter, J. Electroceram., $13,(2004) 385-392$

[8] Y. Li, K. Moon and C. P. Wong, Science., 308(2005) $1419-1420$

[9] T. Maiti, R. Guo, and A. S. Bhalla, J. Appl. Phys., 100(11) (2006) 114109-1-6.

[10] C. Lei, A. A. Bokov and Z. G. Ye, J. Appl. Phys., 101(2007) 084105-1-9

[11] H. Yu and Z. G. Ye, J. Appl. Phys, 103(2008) 034114-1-5

[12] L. Zhang, X. Wang, W. Yang, H. Liu and X. Yao, J. Appl. Phys., 104(2008) 014104-1-5

[13] J. Ryu, S. Priya nd K. Uchino, Appl. Phys. Lett., 82(2003) 251-253

[14] H. L. Du, W. C. Zhu, F. Luo, D. M. Zhu, S. B. Qu, Y. Li and Z. B. Pei, J. Appl. Phys., 104(2008) 044104-1-5

[15] C. J. Stringer, T. R. Shout and C.A. Randall, J. Appl. Phys., 101,(2007) 054107-1-6

[16] H. Ogihara, C.A. Randall and T. M. Susan, J. Am. Ceram. Soc., 90(1) (2009) 110-118

[17] T. Takenaka, K. Maruyama, and K. Sakata, J. JAP, Part 1-Regular Papers Short Notes \& Review Papers.,
$30[9 B](1991) 2236-9$

[18] L. Gao, Y. Huang, Yan hu, hongyan Du, CeramicInternational., 33 (6)(2007) 1041-1046

[19] Liu Yunfie, XUMing, SHI shuzhe, XUHanqiao, YANG Xiaodong, J. Wuhan University of technology-materials Science dition., 22(2) (2007)315-319

[20] A. A. Bokov and Z. G. Ye, J. Mater. Sci., 41(1) (2006) 31-52

[21] B. Beleckas, J. Grigas, S. Stefanovich, Litovskii Fizicheskii sbornik., 202(1989) 29

[22] B. E. Vugmeister, M. D. Glinichuk, Rev. Mod. Phys., 62(1990) 993-1026

[23] T. Badapanda, S. K. Rout, S. Panigrahi, T. P. Sinha, J. Current Applied Physics., 9(4) (2009) 727-731

[24] T. A. Nealon, Ferroelectrics., 76(1)(1987), 377-382

[25] S. A. Ahmed, E. M. M. Ibrahim, S. S. Saleh, Applied Physics A: Materials Science and Processing., 85(2)(2006) 177-184

[26] A. k. Jonsher, K. L. Deori, J. M. Reau and J. Moali, J. Mater. Scien., 14(6)(1979) 1308-1320

[27] P. B. Macdo, C. T. Moynihan, and R. Bose, J. Phy. Chem. Glass., 13(6)(1972) 171-179

[28] J. Liu, Ch-Duan, W. G. Yin, W. N. Mei, R. W. Smith, J. R. Harday, J. Chem. Phys., 119(2003) 2812-19

[29] N. Hirose, A. R. West, J. Am. Ceram. Soc., 79(1996) 1633-164

[30] B.V.Bahugunasaradhi, K. Srinivas, G. Prasad, S. V. Suryanaryana, T. Bhimasankaram, Mat Sci Eng B.,98(2003) 10- 16

[31] Lily, K. Kumar, K. Prasad, R. N. P. Choudary, J. Alloys and Compounds., 453(1-2)(2008) 325-33

[32] R. Y. Sun, S. J. Fan, J. D. Wu and Y. F. Lin., Proc. IEEE. Int. Frequency. Contr. Symp.,(1996) $113-117$

[33] S. Sen, P. Pramanik, R. N. P Choudary, J. Applied Physics A: Materials Science \& Processing., 82(3)(2006) 549-557

[34] R. M. Hill, C. Pickup, J. Mater. Scie., 20(12)(1985) 4431-4444,

[35] M. M. Kumar, Z. G. Ye, J. Appl. Phys., 90(2011) 934-4

[36] V. Hornebecq, J. M. Reau and J. Ravez, Solid State Ionics., 127(2000) 231-240

[37] V. Hornwbecq, Personal communication 